\title{
D. ANTÓNIO DA COSTA, PALADINO DA INSTRUÇÃO POPULAR EM PORTUGAL NO SÉCULO XIX ${ }^{1}$
}

DOI: http://dx.doi.org/10.1590/2236-3459/65288

\author{
Maria de Fátima M. M. Pinto \\ Universidade de Lisboa (ULisboa), Portugal
}

$\cos 8$

\begin{abstract}
Resumo
Neste artigo analisa-se o papel de D. António da Costa no desenvolvimento do ensino público e popular em Portugal, na segunda metade do século XIX. Destaca-se a criação das bibliotecas populares, um dos instrumentos da instrução popular previstos no projeto concebido pelo homem que inaugurou o cargo de ministro da Instrução Pública em Portugal. A sua intervenção ultrapassou a duração deste cargo, iniciandose uma década antes e prolongando-se depois, através da implementação das bibliotecas populares. Conhecedor da realidade do seu tempo e do seu país, D. António da Costa assumiu posições conciliadoras, acreditando que o sucesso das suas propostas dependia da articulação das iniciativas públicas e privadas, laicas e religiosas, num contexto de intervenção política descentralizada.

Palavras-chave: biblioteca popular, instrução popular, instrução pública.
\end{abstract}

\section{ANTÓNIO DA COSTA, A DEFENDER OF POPULAR EDUCATION IN PORTUGAL IN THE XIX CENTURY}

\begin{abstract}
This article analyzes the role of D. António da Costa concerning the development of public and popular education in Portugal in the second half of the nineteenth century. Special emphasis is given to the creation of popular libraries, one of the popular education tools provided in the project designed by the man who was the first Minister of Public Education in Portugal His intervention surpassed the time of this position, starting a decade earlier and extending after it, through the implementation of popular libraries. An expert of the reality of his time and his country, D. António da Costa took conciliatory positions, believing that the success of their proposals depended on the coordination of public and private laic and religious initiatives in a decentralized political intervention scope.

Keywords: popular librarie, popular education, public education.
\end{abstract}

\section{ANTÓNIO DA COSTA, PALADÍN DE LA ÉDUCATION POPULAR EN PORTUGAL EN EL SIGLO XIX}

\section{Resumen}

En este artículo se analiza el papel de D. António da Costa en el desarrollo de la educación pública y popular en Portugal en la segunda mitad del siglo XIX. Cabe destacar la creación de bibliotecas populares,

$1 \mathrm{O}$ texto do artigo foi elaborado a partir da tese de doutoramento, As bibliotecas populares em Portugal: entre representações e práticas - o esboçar de uma missão (1870-1930).

\begin{tabular}{|l|l|l|l|l|l|}
\hline Hist. Educ. (Online) & Porto Alegre & v. 21 & n. 53 & set./dez. 2017 & p. 144-157
\end{tabular}


una de las herramientas de educación popular previstos en el proyecto diseñado por el hombre que inauguró el cargo de Ministro de Educación en Portugal. Su intervención superó la longitud de este post, a partir de la década anterior y la prolongación después de que, mediante la implementación de las bibliotecas populares. Conocedor de la realidad de su tiempo y de su país. António da Costa tomó posiciones conciliadoras, en la creencia de que el éxito de sus propuestas depende de la coordinación de las iniciativas públicas y privadas, seculares y religiosos en un contexto descentralizado intervención política.

Palabras clave: biblioteca popular, educación popular, educación pública.

\section{ANTÓNIO DA COSTA, UN DÉFENSEUR DE L' ÉDUCATION POPULAIRE AU PORTUGAL AU XIXe SIÉCLE}

\section{Résumé}

Cet article analyse le rôle de $\mathrm{D}$. António da Costa dans le développement de l'éducation publique et populaire au Portugal dans la seconde moitié du XIXe siècle. II convient de noter la création de bibliothèques populaires, l'un des outils d'éducation populaire prévus dans le projet conçu par l'homme qui a inauguré le poste de ministre de l'Éducation au Portugal. Son intervention a dépassé la longueur de ce post, à partir d'une décennie plus tôt et prolonger après, en mettant en œuvre les bibliothèques populaires. Connaisseur de la réalité de son temps et de son pays, António da Costa a pris des positions conciliantes, estimant que le succès de leurs propositions dépendait de la coordination des initiatives publiques et privées, laïques et religieuses dans un contexte d'intervention politique décentralisé.

Mots-clés: bibliothèque populaire, éducation populaire, l'éducation publique. 


\title{
Introdução
}

\author{
O seu escrever é para admiração; \\ mas o seu proceder seria para imitação.
} (CASTILHO, 1894, p. 8).

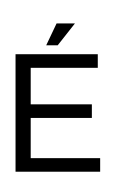
com estas palavras que o amigo, Júlio de Castilho, inicia a biografia de D. António da Costa de Sousa de Macedo, vulgarmente conhecido apenas pela versão abreviada do nome. Apesar do seu percurso pessoal e profissional já ter interessado alguns investigadores, encontra-se ainda espaço para outros olhares, com um enfoque distinto, como o que nos propomos apresentar, a partir de um conjunto de documentos que integram a colecção Castilho do ANTT, incluindo algumas obras da autoria de D. António da Costa.

O trabalho de investigação sobre as bibliotecas populares portuguesas de criação oficial $^{2}$ (entre 1870 e 1930), suscitou uma reflexão sobre o alcance da ação dos responsáveis pela criação destes equipamentos educativos e culturais, entre os quais avulta naturalmente o nome de D. António da Costa.

Neste texto analisamos alguns aspetos da intervenção política e cultural do homem que inaugurou o ministério da Instrução Pública em Portugal, aproveitando o escasso tempo de permanência no cargo de ministro do Ensino (69 dias) para legislar sobre diversas matérias, com destaque para a que lhe era mais cara, a instrução primária, e reservando para as bibliotecas populares um lugar particular.

\section{O contexto social e político}

D. António da Costa era um homem "de família", bisneto do marquês de Pombal e sobrinho do duque de Saldanha, a cujos chamados acudiu por diversas vezes, assumindo-se seu admirador, apesar das diferenças de personalidade que os caracterizavam.

Não obstante assumirmos um olhar onde se coloca maior ênfase ao seu "proceder" do que à análise do contexto familiar e ideológico, não podemos ignorar a importância das suas raízes para a natureza da obra vincadamente social e cristã, própria de um homem de convicções católicas e liberais, que alcançou assinalável protagonismo na articulação entre o Estado liberal e a Igreja, num período marcado pela posição crítica de Roma $^{3}$ relativamente à contaminação das esferas política e religiosa, como forma de reação à civilização moderna e às inerentes ideias de progresso científico e social.

Em traços gerais, o contexto político, económico - social e cultural é o de uma sociedade liberal, onde as teses do Progresso, sustentadas por um ideal de homem perfectível, ganharam um número cada vez maior de adeptos, enfrentando as reservas daqueles que consideravam o acesso ao conhecimento e à leitura um perigo social e apontando o desenvolvimento da instrução popular como um caminho alternativo ao que

2 Incluímos nesta designação as bibliotecas populares que foram criadas na sequência da determinação oficial, estabelecida, primeiro, pelo Decreto de 2 de Agosto de 1870 e depois, durante a I República, pela Lei de 18 de Março de 1911, distinguindo-as das bibliotecas criadas por iniciativa particular e sem apoio do Estado (associações...).

3 O Papa Pio IX mandou publicar, em 1864, a carta encíclica Quanta Cura com o apêndice Syllabus errorum. 
era indicado pelos defensores das ideias conceções mais elitistas. Tornou-se relativamente consensual a ideia de ser vantajosa a existência de uma "unidade cultural", que aproximasse a elite política e os cidadãos, constituindo uma referência estruturante do ideal de Estado-Nação triunfante no século XIX.

Numa outra ordem de ideias, o Fontismo $^{4}$ criou em Portugal as condições necessárias para a consolidação do capitalismo como ordem social hegemónica - o terreno em que são lançados os gérmenes da democracia contém já os elementos de oposição social que condicionarão o funcionamento desse sistema político, gerando no seu seio contradições, para as quais foram encontradas respostas que nos provocam alguma perplexidade.

A ligação de Portugal à Europa tornou-se mais fácil e intensa, devido ao fomento das obras públicas e meios de comunicação que incluíram o comboio, o telégrafo, o cabo submarino e, mais tarde, já nos alvores do século XX, a telegrafia sem fios e o automóvel, facilitando a penetração das ideias no nosso país e a influência dos modelos culturais europeus, sobretudo franceses.

O desafio reservado aos políticos consistia em motivar e escolarizar um público refratário à escola, apesar de aderente às práticas socioculturais da leitura/escrita. A escolarização representava o processo de iniciação à cidadania ativa, mobilizando a ação dos municípios que se regiam sobretudo pela conveniência política.

Paralelamente, ergueram-se também algumas vozes dissonantes tentando agitar as consciências e beliscar o ideal de progresso social assente na crença do imprescindível combate ao analfabetismo, considerado a principal causa do atraso cultural e moral dos portugueses. Salienta-se 0 nome de Adolfo Coelho ${ }^{5}$, o pedagogo da controvérsia, o acérrimo crítico do "utopismo", que não desiste de questionar o sistema vigente, pondo a nu as limitações das sucessivas reformas do ensino secundário e primário e mostrando-se cético quanto às vantagens da escolarização das populações rurais e a utilidade daquilo que ele designa por "sopa económica do espírito" 6 .

\footnotetext{
4 Designação atribuída à política de fomento de obras públicas (caminhos de ferro, estradas, pontes...) promovida durante a governação de (António Maria de) Fontes Pereira de Melo, que se estendeu entre 1851 e 1886, período em que exerceu os cargos de ministro da Fazenda, ministro das Obras Públicas Comércio e Indústria e presidente do Conselho. Apostado em modernizar o país, encetou um conjunto de medidas que possibilitaram a integração de Portugal na circulação mundial de bens capitais e pessoas, aproximando-o da Europa. A política expansionista de Fontes Pereira de Melo, protagonizada por uma classe política dirigente constituída essencialmente por funcionários oriundos da classe média, com predomínio para os diplomados em Direito, representa a nova ordem económica, que pagou um preço elevado pelo progresso obtido: o aumento da dívida pública que deixou o país à beira da bancarrota e com uma acentuada dependência do exterior.

5 Francisco Adolfo Coelho (1847-1919) foi uma figura relevante pelos seus trabalhos no campo da pedagogia, linguística, etnografia e antropologia. Trabalhou em escolas e projetos de diferentes graus de ensino e fundou o primeiro Museu Pedagógico na Escola Normal Superior de Lisboa (1882). A sua participação nas célebres Conferências do Casino (1871) atesta a dimensão polémica da sua obra que teve eco nas propostas republicanas para a reforma do ensino apresentadas por uma Comissão da qual ele fazia parte (1911, junho). Não obstante, o autor manteve vivo o seu espírito crítico, avesso à rigidez e fixação que as leis representam e que não garantiam o sucesso da "missão social" da educação. Na sua opinião, a instrução não era obstáculo ao aumento da criminalidade.

6 O autor sublinha o caráter anedótico deste princípio com os seguintes exemplos: um professor teria chegado a propor, numa conferência escolar em 1869, que ao indivíduo que não soubesse ler fosse concedida apenas "proteção animal". Três décadas depois, num questionário formulado pela Associação dos Jornalistas de Lisboa em Maio de 1902, aventava-se a hipótese de proibir o casamento a todo o indivíduo que não soubesse ler nem escrever. Cf. Adolfo Coelho, Cultura e Analfabetismo, p. 143 e 172.
} 
Não obstante, o "discurso da necessidade" de bibliotecas públicas acessíveis à população das camadas inferiores falou mais alto, evidenciando-se através das alterações introduzidas no estatuto e no regulamento da Biblioteca Nacional, à qual foram atribuidas funções de "leitura publica", pelo decreto de 31 de Dezembro de 1863, que facilitou o acesso a todas as pessoas, dentro de um horário que se estendia das $10.00 \mathrm{~h}$ até ao "sol posto" e permitindo o empréstimo de livros por um prazo de 15 dias. $^{7}$

\section{Preparação das reformas da instrução pública}

A análise do percurso profissional de D. António da Costa permite-nos identificar a causa a que devotou conhecimentos e energias, senão vejamos:

$\mathrm{Na}$ década de 1850, em Leiria, no âmbito das funções de secretário-geral do governador civil, levou a cabo algumas medidas que Ihe permitiram ensaiar o sentido das reformas que ambicionava para o país, entre as quais se contavam a criação do "Centro Promotor da Instrução Popular" (1851) com o objetivo de promover o ensino destinado às camadas inferiores da população, nomeadamente através de aulas noturnas, com recurso ao "Methodo Portuguez", da autoria de António Feliciano de Castilho, que terá tido uma intervenção pessoal nessa iniciativa. Previa ainda a criação de uma biblioteca pública e gratuita na sede de distrito e vários gabinetes de leitura, considerando as necessidades específicas de diferentes grupos sociais.

A criação do jornal $O$ Leiriense obedeceu também à preocupação com a divulgação de dados e ideias sobre o estado da instrução e o sentido da educação em Portugal ${ }^{8}$. Inovadora, a sua obra sobre a "Estatística no Distrito de Leiria" colocou em evidência o atraso de Portugal relativamente a outros países europeus, em matéria de ensino primário e de institutos de leitura visando as camadas populares.

Nas páginas deste periódico, que veiculou em primeira mão o ideário do homem que viria a inaugurar o ministério da Instrução Pública $^{9}$, ficaram registadas as suas preocupações e as propostas para instituir a "educação elementar obrigatória" para todas as crianças, garantida pelas famílias ou, na sua ausência, pelo Estado, "pai de todas as famílias, protetor de todos os direitos, através de "azilos, não como encargos de caridade, mas como instituições de ensino." A sua preocupação com a educação moral e religiosa supera o interesse que denota em combater o analfabetismo, proporcionando instrução primária às crianças das camadas populares, como facilmente se depreende das suas palavras: "Não ensinemos só a leitura, eduquemos principalmente." (O LEIRIENSE, 1856, p. 2).

Nesta intervenção de D. António da Costa importa sublinhar o rasgo de modernidade que representa a sua perceção sobre a importância de controlar alguns serviços complementares e inovadores, indispensáveis para garantir a eficácia da ação política e dominar o poder local: a imprensa e a estatística.

\footnotetext{
7 Diário do Governo de 4 de Janeiro de 1864 - Ministério dos Negócios do Reino - Direcção Geral de Instrucção Pública, cap. X e XI.

8 Do conjunto de ideias expostas por D. António da Costa neste periódico salientamos a iniciativa de fazer uma distribuição gratuita de "livrinhos" pelos alunos das "classes populares", encetada em Leiria e considerada um dos "maiores serviços á instrução primaria" porque "Não basta saber ler, é preciso ter que ler, e ler livros bons."

9 Exerceu o cargo de ministro da Instrução Publica durante apenas 69 dias (22 de Junho $1870-29$ de Agosto de 1870), num governo de ditadura, resultante de um golpe, chefiado pelo duque de Saldanha.
} 
O seu desempenho catapultou-o para a esfera da política nacional, muito embora em representação do referido distrito, e permitiu-Ihe apresentar o "Projeto de Reforma da Instrução Primária", onde se salientam os pressupostos sociais, morais e de descentralização do ensino, deixando bem explícita a ligação entre educação e religião ${ }^{10}$.

Em 1860 integra a direção geral da instrução pública do Ministério do Reino, na qualidade de primeiro-oficial, e é nesta década que aprofunda as suas ideias sobre a necessidade de um Ministério da Instrução Pública, publicitadas num texto com esse título, onde esclarece sobre a autoria da ideia de transformar a Direção Geral num Ministério, em que coubesse mais do que uma pasta, segundo o projeto apresentado pelo então ministro da Marinha, Latino Coelho, e que lhe merece todo o apoio, pelo que significa de valorização para a Instrução Pública e de avanço na política descentralizadora.

Ainda que a sua ideia fosse mais avançada, "pedindo um ministerio de instrucção publica independente", falou mais alto a sua faceta de homem "equilibrado", conciliador, "que interpretou sempre a Lei pelo lado favorável" (CASTILHO, 1894, p. 6) e que por isso mesmo entende que, "[...] não sendo este o momento opportuno, adoptámos a idéa do ministerio cumulativo." (COSTA, 1868, p. 12). Desta forma, segue em frente na sua justificação da necessidade de um Ministério da Instrução Pública para promover o desenvolvimento do ensino, analisando os aspetos sociais e financeiros da questão, com destaque para o que ao ensino primário diz respeito ${ }^{11}$, e dando como exemplo outros estados europeus que já se encontravam nesse caminho.

É interessante registar a sua crítica ao excesso de burocracia, uma força negativa na eficácia das instituições e um entrave ao progresso das "obras" que ele considera fundamentais. Das palavras escritas importa reter a identificação dos serviços que requerem reformas, para inferir da natureza das suas preocupações:

[...] uma das mais pestiferas chagas da nossa organisação, ou desorganisação, é o nefando reinado da papelada.

Mais obras e menos palavras. Não achâmos que o paiz tenha funcionalismo excessivo; o que tem é funccionalismo excessivamente accumulado. Há muitas repartições do estado que dispensariam parte do seu funccionalismo, simplificado o expediente; mas tambem ha muitos serviços que seria indispensavel crear ou reorganisar, e apontaremos entre eles a reforma penitenciaria, a beneficencia, a estatistica, a inspecção e outros [...].

(COSTA, 1868, p. 12).

No entendimento de D. António da Costa, era imprescindível uma articulação destes serviços com o projetado Ministério da Instrução Publica, que foi criado pouco tempo depois, em 1870, na sequência da tomada do poder pelo duque de Saldanha que levou consigo para formar governo, o sobrinho, especialista em assuntos de instrução

$10 \mathrm{Na}$ opinião de Fernando Catroga, ele é um lídimo representante do "paradigma cristológico", o que significa dizer que a sua ação se situou no campo do "catolicismo social/liberal". Para D. António da Costa a perfetibilidade que se almejava alcançar para o homem passava pela liberdade e esta realizava-se em pleno no cristianismo.

11 "A instrucção primaria, dotada entre nós tão mesquinhamente, que apenas é contemplada com a quarta parte da dotação geral da instrucção e estabelecimentos literários [...] mais de 40:000\$000 réis na dotação geral da instrucção publica deixam de ser applicados annualmente á desgraçada instrucção primaria, podendo aliás com esta somma crearem-se mais quatrocentas e cincoenta cadeiras, ou quarenta edificios escolares, ou o ensino profissional, ou o que mais urgiria, como a primeira necessidade da instrucção elementar, uma organisação da inspecção local em todo o reino." 
pública e popular, dando-lhe oportunidade para avançar com as ambicionadas reformas.

\section{As bibliotecas populares e a instrução primária}

As bibliotecas populares começaram a ser solicitadas em Portugal na segunda metade do século XIX, considerando-se um instrumento indispensável para assegurar o progresso intelectual dos grupos com menos posses económicas, para quem a compra de livros representava certamente um esforço que estava acima das suas possibilidades.

Pela mesma altura, em 1865, Manuel Pinheiro Chagas publicou um artigo intitulado "bibliotecas populares", na sequência de uma outra matéria centrada no problema da instrução primária em Portugal, que ocupa também grande parte deste texto, salientando a situação dos professores, os principais agentes do ensino, que eram desconsiderados, mal pagos, estando por isso pouco motivados para a implementação de reformas.

No que concerne à leitura e às bibliotecas, o articulista utiliza exemplos estrangeiros, sobretudo franceses, para inspirarem as iniciativas a realizar em Portugal: bibliotecas paroquiais, escolares ou municipais "[...] são o complemento indispensavel de um bom systema de instrucção primaria!", mas que carece acompanhamento noutras etapas da vida para que não se perca o investimento inicial. Esta razão suscita ao autor as seguintes considerações:

[...] é indispensável entre nós a creação de bibliothecas populares; tome o governo a iniciativa [...] Desenvolva a instrucção primaria, consiga que todos saibam ler, e não favoreça a creação de bibliothecas, a publicação económica de livros, e não fez mais do que levantar o povo o lamançal da ignorância, fazer-lhe dar dois passos vacillantes, e deixal-o cair de novo na orla extrema do tremedal. (PINHEIRO CHAGAS, 1865, p. 126).

À semelhança de outros escritores, pedagogos e políticos contemporâneos, a sua ideia evidencia a preocupação com a educação moral dos mais desfavorecidos e a busca de soluções para o problema é analisada no contexto do desenvolvimento da instrução primária, ainda que num enquadramento que se nos afigura idealista e romântico, assumindo a forma de "combate" entre "a moralidade e a devassidão, a intelligencia e a ignorancia." representadas pela escola "com a sua pequenina bibliotheca" e a "taverna, onde se aninham as torpes tentações". (PINHEIRO CHAGAS, 1865, p. 126-132).

Num registo mais objetivo, que se assume como um diagnóstico da situação do ensino em Portugal, D. António da Costa traça o panorama da realidade portuguesa, deficitária no campo cultural e educativo e, entre as múltiplas falhas, identifica a inexistência de bibliotecas populares:

Um paiz que no seculo XIX não possue uma só cadeira de ensino primario superior nem profissional, [...] que não organisou ainda a sua instrucção primaria na base indispensavel da localidade, [...], cuja media de creanças do sexo masculino é de 3 para 100 habitantes, e do sexo feminino de 1 para 100; um paiz que não tem inspecção local, e apenas a sombra de inspecção districtal, que não tem bibliotecas populares, que não distribue livros, que não ensina ao povo nem desenho, nem canto, nem principios de agricultura e industria; um paiz cujo magisterio primario morre de fome, [...]; um paiz n'estas circumstancias não é um paiz europeu, digamo-lo com profundo desgosto, é um paiz semibarbaro. (COSTA, 1868, p. 14). 
Eram estes os contornos do contexto social e cultural que acolheu as bibliotecas populares, oficialmente criadas pelo Decreto de 2 de agosto de 1870, através de um "[...] sistema mixto oficial, municipal e particular." Estava em causa o aproveitamento das iniciativas particulares, incluindo a intervenção da Igreja católica que D. António da Costa gostaria de recuperar, conciliando-as com a organização estatal mas privilegiando a valorização de um sistema descentralizado.

No preambulo do Decreto que instituiu as bibliotecas populares explicita-se a sua função e o(s) público(s) a que se destinavam: "A biblioteca popular completa d'este modo a escola popular, porque a boa leitura moralisa, eleva a alma e aperfeiçoa o trabalho de todos em geral, e de cada industria ou officio em particular." (DECRETO de 2 de Agosto de 1870).

O objetivo era responder às necessidades de leitura de quem já conseguira "a victoria do aprender" e tinha por isso "sêde de leitura", facilitando o acesso aos livros a quem tivesse mais dificuldade em deslocar-se para fora de casa, através da leitura domiciliária, que interessaria sobretudo às mulheres e às crianças ${ }^{12}$.

O desafio assumido por D. António da Costa de criar bibliotecas populares "[...] para todos e para cada um", consubstancia uma abordagem do lema de cariz humanístico-científico (MAGALHÃES, 2010, p. 442), ensinar tudo a todos, que ganha projeção na Modernidade, gerando fortes tensões de caráter social e político que os governos não estavam preparados para resolver, como também não conseguiram lidar de forma racional e coerente com a matriz dicotómica subjacente ao projeto de criação de bibliotecas populares, apoiado por monárquicos e republicanos durante a monarquia constitucional, até 1910, e retomado, depois, pela Primeira República.

D. António da Costa conhecia as iniciativas similares levadas a cabo noutros países europeus e nos EUA, pese embora as especificidades dos vários institutos de leitura que não são referidas. A gratuitidade do acesso à leitura é garantida pela legislação, mas apenas na fase inicial "[...] para facilitar e attrahir nos primeiros tempos [...]".

Apesar da curta duração, o governo presidido pelo duque de Saldanha, com D. António da Costa no cargo de ministro da Instrução Pública, deu a lume um conjunto de leis que visavam mudar o sistema de ensino, em particular a instrução primária e popular, como admitiu o seu autor, ao afirmar que "[...] de todas as reformas decretadas, a da educação era a mais grave, e levava por intuito principal estabelecer uma verdadeira educação social para o povo todo." (COSTA, 1871, p. 225). Porém, a queda do governo dos 100 dias, pôs termo ao Ministério da Instrução Pública e representou a revogação de todos os diplomas legais promulgados por D. António da $\operatorname{Costa}^{13}$, exceto o que se refere à criação das bibliotecas populares que foi regulamentado pelo governo que the sucedeu.

\footnotetext{
12 No "Relatorio" que antecede o decreto pode ler-se o seguinte: “... a biblioteca entra-lhes por assim dizer em casa, procura e instrue principalmente a mulher e a creança."

13 No entanto, poucos meses depois, em 11 de março de 1871, foi apresentada à Câmara dos Deputados uma proposta de Lei com a reforma da Instrução Primária que se assumia herdeira direta dos "... principaes fundamentos d'aquelles Decretos [...]", como se pode ler no relatório que precede o documento oficial, do que D. António da Costa discordou em absoluto, rejeitando essa paternidade e explicando as diferenças entre elas: "A base fundamental da minha reforma não era o systema municipal da actual proposta de Lei: era completamente diversa, e nova. Consistia no capital escolar, e este fundado na parochia. A ingerência municipal era provisoria. [...]”. Cf. CASTILHO, Júlio de, D. Antonio da Costa: Quadro Biographico-Litterario, p. 88.
} 
A explicação para tal facto pode encontrar-se na biografia escrita por Júlio de Castilho: "[...] porque já tinha creado profundas sympathias, a instituição das Bibliothecas populares." (CASTILHO, 1894, p. 101). Devidas em larga medida à iniciativa das câmaras municipais, as "bibliothecasinhas para o povo" contaram desde o início com o apoio de figuras e instituições relevantes, assim como doadores de diferentes proveniências, incluindo o próprio criador desta instituição que encarnava a figura do benemérito, recolhendo junto de amigos ou comprando livros porque "[...] elle, até mesmo depois de cahido, continuava a auxiliar, como bom guia, a sua querida fundação." (CASTILHO, 1894, p. 101).

O reconhecimento pela dedicação a esta causa chegava a D. António da Costa de diversos pontos do país ${ }^{14}$, mesmo porque a ligação institucional à Instrução Pública e Popular $^{15}$ permaneceu nas décadas de 1870 e $1880^{16}$, a par do seu investimento na intervenção política/pública e principalmente no domínio da escrita ${ }^{17}$ : três vertentes que à primeira vista se afiguram distintas mas que ele manteve sempre interligadas, assim como articulou os seus ideais e princípios com as preocupações sociais e ambos se foram ajustando às realidades. Esta atuação inscreve-se numa "cultura política res publicana", projetada nas diversas dimensões de que se revestia a reforma da instrução pública: universalismo, modernidade (liberalismo), caridade (amor cristão), liberdade, progresso, educação e instrução, municipalização/descentralização ${ }^{18}$.

No conjunto de quarenta e uma bibliotecas populares concedidas pelo Estado, entre 1870 e 1886, apenas onze estavam a cargo das escolas ou de associações afins. A maior responsabilidade cabia aos municípios, com vinte e nove bibliotecas populares, e apenas duas dependiam das juntas de paróquia.

A natureza do fundo documental destas bibliotecas atesta a dupla função que the é cometida pelo Decreto de 2 de Agosto de 1870: devia ter "duas classes de obras", as que continham conhecimentos gerais, onde se incluía também a literatura e as que tratavam de assuntos específicos das diferentes áreas profissionais (e económicas), no sentido de responder aos interesses de todos e de cada um. Para a realização plena

14 Para a criação da biblioteca popular de Monchique, por iniciativa dos moradores locais, em 30 de novembro de 1876, recorre-se à "protecção" de D. António da Costa solicitando a oferta das suas interessantes produções literárias. Cf. ANTT, Collecção Castilho, Cx. 33, M.1, № 1. Adriano de Sá, escreve de Aldeia Galega em 15 de junho de 1887, agradecendo uma oferta e intitula-o de "fervoroso apóstolo da instrução", o "sabio Messias das escolas que procura regenerar os póvos cultivando-lhes o espirito, o incançavel protector das instituições de oiro [...]", Cf. ANTT, Collecção Castilho, cx. 20, maço 10, doc. 15.

${ }^{15}$ A sua escolha para chefiar o Ministério da Instrução Pública foi apoiada por um abaixo-assinado levado a cabo por uma "comissão" de cerca de 35 pessoas, onde se incluíam 7 mulheres. Cf. ANTT, Collecção Castilho, cx. 20, maço 12, doc. 4.

${ }^{16}$ Aposentou-se em 1886, com a categoria de chefe de repartição do ensino superior, no mesmo ministério de Instrução Pública. Antes, porém, teve de enfrentar um processo com a acusação de faltas injustificadas e incumprimento de funções, por um extenso período de tempo situado entre 1871 e 1879. D. António da Costa reagiu publicamente com uma declaração por ele denominada Ao meu paiz, onde desmonta juridicamente o processo, apoiando a defesa da sua idoneidade nos testemunhos de duas dezenas de amigos que abonaram a favor da sua dedicação ao trabalho e à causa da instrução pública, mesmo num contexto difícil, de sofrimento provocado pela doença prolongada que o atacava, o reumatismo. Cf. D. António da Costa, Ao meu paiz, doc. 18, p. 42-50.

17 Um admirador de Ferreira do Alentejo, Alexandre Cezar M. Ruiz, numa carta datada de 9 de abril de 1885, a propósito da sua obra Auroras da Instrução pela Iniciativa Particular, compara-o a Vítor Hugo o "avô da literatura moderna". Cf. ANTT, Collecção Castilho, cx. 20, maço 10, doc. 13.

${ }^{18}$ A ideia é desenvolvida por Ernesto Castro Leal, no artigo D. António da Costa e o Liberalismo Católico. In: Liberalismo e Antiliberalismo, p. 35. 
deste ideal estabelecia-se a leitura domiciliária, permitindo às mulheres e às crianças um acesso mais fácil à instrução e à leitura (art.ํㅜㅇㅜ).

Esta iniciativa assenta numa conceção descentralizada do poder e desloca para as câmaras municipais a principal responsabilidade pela criação e financiamento das bibliotecas populares, muito embora envolvesse outras entidades, nomeadamente as de caráter educativo, e reservasse para o Estado a competência intelectual que se traduzia na escolha dos livros que integravam os seus acervos (art. $.014^{\circ}$ ).

Nesta ordem de ideias, foram entregues pelo Estado às bibliotecas populares, conjuntos de livros, devidamente identificados e com algumas semelhanças na sua composição. Às câmaras municipais competia a atribuição de um subsídio de $50 \$ 000$ para a manutenção desses equipamentos. A interrupção do seu funcionamento implicava a devolução dos livros carimbados com a identificação de "propriedade do estado".

Em todos os diplomas legais desde o decreto de 2 de agosto de 1870, da autoria de D. António da Costa, é evidente a relação entre estes institutos de leitura pública e a instrução popular/pública, considerando-se um complemento da escola, acrescido de responsabilidades éticas e morais $^{19}$, o que deve ser entendido no contexto de uma sociedade liberal em que o trabalho era considerado o maior dos bens e o progresso económico, social e cultural uma finalidade suprema.

Importa salientar que a primeira referência num orçamento de Estado a uma verba destinada à compra de livros para as "bibliotecas populares" surge em 1877, sendo da responsabilidade do chefe de repartição da instrução primária, sem contudo ter alcançado quaisquer resultados práticos, apesar de o quadro de realizações das bibliotecas populares ser considerado "modesto", de acordo com a apreciação que fundamenta a referida proposta.

A Lei eleitoral de 1878, gizada pelo ministério de Fontes Pereira de Melo, visava alargar as bases de apoio/legitimação do regime monárquico - constitucional e daí a importância da escolaridade obrigatória que significa a imposição da condição cultural (e familiar) sobre a condição económica, própria do voto censitário.

$\mathrm{Na}$ prática, o número de eleitores quase duplicou num período de cinco anos, entre 1875 e 1880. Este facto é indissociável da projeção alcançada pela instrução popular, que revestiu também um carácter menos formal, através de cursos noturnos e palestras destinadas a iniciar os adultos analfabetos na prática da leitura e da escrita e a transmitir-Ihes conhecimentos básicos, essenciais, preparando-os para o exercício da cidadania.

D. António da Costa foi um homem de uma causa e de um tempo, o que justifica o seu entusiasmo pela "pedagogia moderna"20, mas também os traços de uma mentalidade que se revia no caráter elitista da cultura, como nos deixa perceber a crítica de Júlio de Castilho às práticas bibliófilas de D. António da Costa, que dividia os livros entre os que eram para guardar, estimar, "[...] sem Ihes tocar com a ponta de um dedo [...]" [os bons] e

\footnotetext{
${ }^{19}$ A biblioteca popular representa uma "influencia salutar sobre a morigeração das classes operarias", como é referido na Circular de 22 de fevereiro de 1875 sobre a Inspeção das Escolas e Métodos de Ensino.

20 D. António da Costa responde a Júlio de Castilho, afirmando: "[...] pertenço à pedagogia moderna [...] estou positivista, por índole e pelo conhecimento dos processos modernos. Esta é a minha orientação. Sou um Novo. Como tal, lidero a Idea Nova. Tu vaes em camº. errado , como eu ia; mas emendei-me. [...] Mandei ao diabo os romantismos, as flores, as madrugadas [...]", s.d. (agosto ? 1889 ), Cf. ANTT, Collecção Castilho, Cx. 55, mç. 5, no 11.
} 
os que serviam para manusear, ler e reler, "[...] os maus, os indiferentes". E, num tom irónico, Júlio de Castilho apresenta a sugestão:

Tu, o apóstolo da instrução, o creador das Bibliothecas populares, devias mandar arranjar em cada Bibliotheca uma cafurna onde se escondessem a todos os olhos os melhores autores, como prova de respeito, deixando que fossem lidos apenas os péssimos. (COLLECÇÃO CASTILHO, cx. 55, maço 5, carta 14, 24/10/1889).

Estas observações surgiram em resposta ao facto de D. António da Costa ter admitido que não tinha aberto o livro que Júlio de Castilho acabara de publicar, Lisboa Antiga, para não o estragar, dada a beleza do exterior, provocando os comentários do amigo, que questionara o que ele denominava de "exageros de bibliófilo". Mesmo considerando o tom provocatório, próprio de quem se está a dirigir a um amigo muito íntimo e que deseja verdadeiramente saber a sua opinião sobre a obra publicada, as considerações de Júlio de Castilho enformam, ao mesmo tempo que interrogam (na pessoa daquele que foi o responsável direto pela sua institucionalização), uma conceção de biblioteca e de leitura dicotómica, que criou raízes mais fortes e duradouras do que a longevidade das várias "bibliothecasinhas para o povo", que surgiram na sequência da legislação da sua autoria.

\section{Considerações finais}

A análise da correspondência mantida entre estas duas figuras de relevo no panorama cultural e político da sociedade portuguesa oitocentista, focando diferentes assuntos, num registo informal e descomprometido, permite-nos esboçar representações das vivências e das preocupações dos seus intervenientes. A riqueza deste manancial de informação evidencia dúvidas e contradições desses atores, que suscitam interrogações mas sugerem também algumas respostas:

Nesse sistema misto que D. António da Costa defendia para a tutela das bibliotecas populares, qual o papel que ele reservava para as juntas de paróquia? Seria mais ou menos relevante do que o que competia às câmaras municipais?

Fazendo fé nas palavras do seu biógrafo (Júlio de Castilho), D. António da Costa não reconheceu a autoria que Ihe foi atribuída em relação à reforma da instrução primária, nomeadamente porque a ação das juntas de paróquia fora substituída pela intervenção municipal. Não obstante, quando Júlio de Castilho o informou da sua intenção de fundar em Odivelas uma Biblioteca Popular e partilhou a ideia de pedir apoio à junta de paróquia para a festa de inauguração, ele desaconselhou-o e sugeriu que o fizesse de forma "livre", rematando com o seguinte desabafo: "Tu sabes lá o que é uma junta de parochia!" (COLLECÇÃO CASTILHO, Cx. 55, maço 5, no 11).

À medida que organizámos estas notas sobre D. António da Costa, fomos tomando consciência da complexidade da sua personalidade e da certeza de não ser plausível confinar a representação daquele que foi o primeiro ministro da Instrução Pública em Portugal, a qualquer uma das dimensões da sua atuação, nem tão pouco à ideologia e princípios morais que pautaram a sua intervenção social, política e cultural. A ele ficou a dever-se também a valorização do papel das mulheres no ensino, abrindo espaço para a sua afirmação social e política. Não se poupou a elogios das figuras femininas suas contemporâneas que assumiram a função de educadoras na escola 
pública, como foi o caso de Maria José Canuto, que D. António da Costa refere como exemplo e modelo a seguir, defendendo a sua ideia de uma necessária "feminização" do ensino. ${ }^{21}$

Conhecedor da realidade do seu tempo e do seu país, D. António da Costa assumiu posições essencialmente conciliadoras, acreditando que o sucesso das suas propostas dependia da capacidade de articulação das iniciativas públicas e privadas, laicas e religiosas, pelo que privilegiava a intervenção descentralizada. Ao mesmo tempo, criticava a burocracia institucional que não aproveitava as boas vontades para levar avante os projetos/iniciativas dos beneméritos, revendo-se no binómio: filantropia versus ação institucional.

D. António da Costa não deixa nunca de defender a importância da sua causa, a instrução popular, pública, de que as bibliotecas populares eram um dos instrumentos, mas mostra-se consciente de como são modestos os resultados alcançados, comparativamente aos países estrangeiros que ele vai citando, ainda que com algumas interpretações pouco rigorosas, como quando se refere aos EUA como um dos exemplos de desenvolvimento das bibliotecas populares.

O seu empenho verdadeiro no melhoramento do ensino popular e público foi reconhecido por Eça de Queirós, uma das figuras que ergueu a voz crítica e dura para condenar a política instituída em Portugal no início da década de 1870 , em particular no que respeitava à instrução, classificada de "canalhice pública". Neste panorama que Eça considerava ser um "grande desastre da civilização!", o autor destaca de forma positiva a intervenção de $\mathrm{D}$. António da Costa, muito embora se refira apenas à sua produção teórica:

Desta indiferença profunda e bestial que há pela instrução, devemos exceptuar os excelentes trabalhos de Sr. D. António da Costa. Os seus livros, escritos com uma exacta ciência e com um altivo sentimento, são o protesto da civilização e a desforra do espírito. (QUEIRÓS, 1978, p. 105).

Apesar da sua experiência governativa ter sido muito breve e do entusiasmo ter esmorecido com o passar dos anos, podemos afirmar que a ideia das bibliotecas populares vingou e ganhou espaço no campo político e social, o que justifica que tivesse sido sucessivamente retomada ao longo do século $X X$, ainda que com as adaptações próprias dos diferentes contextos políticos, sociais e ideológicos.

\section{Referências}

ARQUIVO NACIONAL DA TORRE DO TOMBO (ANTT). Collecção Castilho. Cx. 20, maços 10, 12; Cx. 33, maço 1; Cx. 55, maço 5.

CARVALHO, Rómulo de. História do ensino em Portugal: Desde a Fundação da Nacionalidade até ao Fim do Regime de Salazar-Caetano. Lisboa: Fundação Calouste

\footnotetext{
${ }^{21} \mathrm{Na}$ verdade, Maria José Canuto era uma figura feminina conhecida nos meios pedagógicos da capital e com uma reputada atividade no domínio da escrita. (1812-1890). É referida por António Feliciano de Castilho, o poeta - pedagogo, autor do "Método Português" de leitura que teve nesta professora uma digna representante, contrariando a resistência oferecida por parte de alguns professores, com o brilho dos resultados obtidos pelos seus alunos e de que Castilho faz alarde, em 1857, no no 3 da Revista da Instrução Pública para Portugal e Brasil. In: FERNANDES, Rogério. Um Projecto de jornalismo pedagógico luso-brasileiro no século XIX (1857-1858). História da Educação, v. 7, p. 30-32, abril 2000.
} 
Gulbenkian, 2008.

CASTILHO, Júlio de. D. Antonio da Costa: Quadro Biographico-Litterario. Coimbra: Imprensa da Universidade, 1894.

CASTRO, Maria Helena Ribeiro de. D. António da Costa: político e pedagogo. In: FERREIRA, A. M.; ALMEIDA, J. M. (Dir.) Religião e Cidadania: protagonistas, motivações e dinâmicas sociais no contexto ibérico. Lisboa: Universidade Católica Portuguesa, CEHR, 2011, p. 165-184.

CATROGA, Fernando. O republicanismo em Portugal: Da Formação ao 5 de Outubro de 1910. Lisboa: Casa das Letras, 2010.

COSTA, D. António da. Ao Meu Paiz. Lisboa: Typ. Universal de T. Quintino Antunes, 1880.

Auroras da instrucção. Lisboa: Imprensa Nacional, 1884.

História da instrução popular em Portugal desde a fundação da monarchia até aos nossos dias. Lisboa: Imprensa Nacional, 1871.

. Necessidade de um Ministerio de Instrucção Publica. Lisboa: Imprensa Nacional, 1868. Disponível em <http://www.gutenberg.org/files/32794/32794-h/32794-h.htm> Acesso em: 5 jun. 2016.

. O christianismo e o progresso. Lisboa: Imprensa Nacional, 1868.

FERNANDES, Rogério. Ensino primário e debate curricular: o projecto de D. António da Costa em 1857. In: Ensaios em homenagem a Joaquim Ferreira Gomes: Núcleo de análise e intervenção educacional da Faculdade de Psicologia e Ciências da educação da Universidade de Coimbra. Coimbra, 1998, p. 291-209.

. Marcos do processo histórico da alfabetização de adultos em Portugal. Colóquio Educação e Sociedade, Lisboa, n. 2, p. 115-144, fev. 1993.

GOMES, Joaquim. Um bisneto do Marquês de Pombal promotor da instrução primária. In: Estudos de História e de Pedagogia. Coimbra: Livraria Almedina, 1984, p. 105-117.

GOUVEIA, Medina de. D. António da Costa, o cristianismo e o progresso: I - Percurso pedagógico e político. II - A resposta a Antero de Quental. Separata da revista Brotéria, n. 4, p. 353-363, v. 5/6, v. 158, p. 461-478, abril/maio/jun. 2004.

LEAL, Ernesto Castro, D. António da Costa e o liberalismo católico. Liberalismo e antiliberalismo, Lisboa, Centro de História da Universidade de Lisboa, 2013.

O LEIRIENSE, 1855, n. 121,1 set.; 1856, n. 223-225, 3, 6 e 10 de Setembro.

MAGALHÃES, Justino Pereira de. Da cadeira ao banco: escola e modernização (Séculos XVIII-XX), Lisboa: EDUCA, 2010.

MATOS, Sérgio Campos. Política de educação e instrução popular no Portugal oitocentista. Separata da Clio - Revista do Centro de História da Universidade de Lisboa, Lisboa, Edições Colibri, p. 85-107, 1997.

QUEIRÓS, Eça. Uma campanha alegre. De "As Farpas", v. II. Porto: Lello \& Irmão Editores, 1978.

RAMOS, Rui. O método dos pobres: educação popular e alfabetização em Portugal (Séculos XIX e XX). Colóquio Educação e Sociedade, n. 2, 68, p. 41, fev. 1993.

RAMOS, Rui; SOUSA, Bernardo de Vasconcelos e; MONTEIRO, Nuno Gonçalo (Coords.). História de Portugal. Lisboa: A Esfera dos Livros, 2012, p. 521-548.

REBELO, Carlos Alberto. A difusão da leitura pública: as bibliotecas populares (1870- 
1910). Porto: Campo das Letras, 2002.

REIS, Jaime. O Analfabetismo em Portugal no século XIX: uma interpretação. Colóquio Educação e Sociedade, n. 2, fev. 1993.

VINAO FRAGO, A.: A la cultura por la lectura. Las bibliotecas populares (1869-1885). In: GUEREÑA, Jean-Louis; TIANA, Alejandro F. (Eds.): Clases populares, cultura, educación. Madrid: Casa de Velázquez, 1989, p. 301-335.

MARIA DE FÁTIMA M. M. PINTO é doutoranda do Instituto de Educação Universidade de Lisboa.

Endereço: Alameda da Universidade, 1649-013 - Lisboa - Portugal.

E-mail: famamapin@gmail.com

Recebido em 07 de junho de 2016.

Aceito em 16 de outubro de 2016. 